\title{
Sceptical Overkill: On Two Recent Arguments Against Scepticism
}

\author{
KIERON O'HARA
}

\section{Introduction: Three constraints for an anti-sceptical argument}

This paper is a discussion of a recent attempt by Crispin Wright (Wright 1991; page references to this work unless stated) to force at least some varieties of external world scepticism to succumb to a "head-on, rational response", contrary to well-known expressions of pessimism by, for example, Sir Peter Strawson and Barry Stroud. The varieties of scepticism in question are those that involve positing a "purportedly undetectable but cognitively disabling state", such as the state imposed by Descartes' malicious demon, in which a sufferer is unable to tell whether or not his or her experiences are caused by items in his or her perceptible environment, as opposed to some disassociated cause; the argument is completed by noticing that, if such a state were possible, then no-one could have complete confidence that he or she were not in such a state.

Wright's project is more ambitious than the simple defeat of such a sceptical argument in debate; he claims, and I agree, that a generalised defeat would itself have to be achieved within three constraints.

The reply must not be aimed solely at versions of scepticism that only attack knowledge. Against such an attack, the proper response is the "Russellian Retreat": "we can live with the concession that we do not, strictly, know some of the things we believed ourselves to know, provided that we retain the thought that we are fully justified in accepting them" (p. 88). What we should not tolerate are arguments that claim to undermine the distinction between grounded, earned beliefs, and ungrounded, dogmatic beliefs.

The reply must not be ad hominem. We must not "be content to rely on attacks on the stability of the conclusion, or on the mutual coherence of the premises which are used to support it. That is good strategy against an opponent; but defusing (the sceptical) paradox demands a properly detailed diagnosis and exposé of its power to seduce." (p. 89)

The reply must undermine the sceptic's argument; a draw is no good. "If I find it totally unacceptable to think that none of my opinions about the external world, for instance, has any ground, it is hardly a comfort to be told that the case has been overstated-that it is merely that I have no justification for thinking that the situation is any better than that." (p. 89)

For our purposes here the salient constraint is the second one. The anti-sceptical argument needs to be highly general, and capable of coping with a large number 
of significant variants. Wright's strategy is to "give" the sceptic almost everything he or she wants, and then show that, even in circumstances maximally congenial to the sceptic, there will be a large number of beliefs the holding of which is warranted. We will suggest in the course of this paper that, arguably, the sceptic has been given too much, and is able to make extremely substantial and disturbing inroads into our epistemological security; these inroads ultimately cause difficulties for the sceptic as well, but not in such a manner as to provide the rest of us with any comfort.

We will claim that what Wright, and his commentator Anthony Brueckner (Brueckner 1992) have overlooked is the sceptic's insistence that any epistemological warrants we gain on the basis of perceptual experience are always conditional on the sceptical hypothesis being false, and we will try to show that, if proper attention is paid to this principle (in the spirit of providing maximally congenial circumstances for the sceptical germ to breed), the position with regard to scepticism is much worse than originally imagined. The structure of the paper is as follows. We defer discussion of Wright's main argument until $\S 3$. In $\S 2$ we discuss an argument of Brueckner's that, if successful, would undercut Wright's argument; Brueckner tries to show that Wright, in his generosity, has given the sceptic a completely implausible premiss. $\$ 4$ sets out the sceptical response to Wright. $\S 5$ is a Wright-inspired reply to the sceptic; we give the last word to the sceptic in $\S 6$.

However, we begin by supplying some definitions; during the course of Wright's complex attack, much technical equipment is assembled, and it will help to avoid the peppering of the main text with explanations if the definitions are given in advance.

\section{Some Definitions}

Warranted Belief: This is an epistemological notion which is vulnerable to the sceptical argument, yet important enough to meet the first constraint. We should not be prepared to give up this notion and perform an analogue of the Russellian Retreat. Finding such an epistemological notion proved more difficult than might have been thought-Wright's $\$$ III is devoted to the search. In the arguments to follow, we use $R x t[P]$ to mean: $x$ has available at $t$ a warrant to believe $P$ (not that $x$ actually believes $P$ at $t$ ).

Proper Execution Principle: "If the acquisition of a warrant to believe a proposition depends on the proper execution of some procedure, then executing the procedure cannot give you any stronger a warrant to believe the proposition in question than you have independently for believing that you have executed the procedure properly." (p. 99)

The Rule of Transmission: This is the first of two rules for the warranted belief operator $\mathbf{R}$, and states that if we have:

$$
R x t\left\{A, \ldots, A_{\mathrm{n}}\right\} ;\left\{A, \ldots, A_{\mathrm{n}}\right\}+\mathrm{B}
$$

we can assert:

$R x t$ [B]. 
I am not sure that I go along with an unrestricted version of this rule. However, in what follows, only single applications of modus ponens are brought within its scope, and this is relatively uncontroversial.

The Rule of Iterativity: The other rule for the warranted belief operator states that if we have:

$$
\text { Rxt }[A]
$$

we can assert:

$$
\operatorname{Rxt}[R x t[A]] \text {. }
$$

Phenomenological Smoothness: "A state or series of states of consciousness is phenomenologically smooth just in case any normally experienced and reflective subject would find no cause therein to suspect that he was not perceiving and thinking perfectly normally." (p. 106)

Maundering: We say " $x$ is maundering at $t(M x t)$ just in case $x$ is then in a phenomenologically smooth state which, like dreaming, necessarily precludes the causal conditions for perception but, in addition, likewise precludes the causal conditions of competent intellection." (p. 106)

This last definition of maundering is introduced because the usual sceptical state-dreaming-is not maximally congenial for the sceptic since, although dreaming precludes perceiving, it does not necessarily preclude competent intellection. With these preliminaries out of the way, we can begin our discussion.

\section{Brueckner's quick argument}

Brueckner's paper is premised on the assumption that the sceptical state under examination is dreaming; we shall keep to the spirit of Wright's project and talk of maundering. No serious damage is done to Brueckner's arguments as a result. Wright allows the sceptic two important premises. The first expresses the nagging doubt that at no time does anyone warrantedly believe that they are not maundering.

\section{P1**) not: $R x t$ [not: $M x t]^{1}$}

The second depends on the following thought: since maundering was defined expressly to exclude competent intellectual function, then, for all $x$ and $t$, where $Q$ is any proposition which $x$ has no grounds for believing before $t$, and can acquire a warrant to believe at $t$ only by competent intellection, we have that

2**) If $R x t[Q]$, then not: $M x t$

Since, for Wright, there seems to be no reason why we should not allow the justifying train of thought to $x$ at $t$, we have our second premiss.

P2**) $R x t$ [If $R x t[Q]$, then not: $M x t]$

${ }^{1}$ The numbering of these propositions is retained from Wright (1991). 
Brueckner wishes' in his paper to focus on the premiss P1**2. Support for this premiss is found at pp. 99-100 and p. 107, but Brueckner remains unconvinced that $\mathrm{P} 1^{* *}$ need be conceded at all. His point is that Wright relies on the Proper Execution Principle (PEP) without actually justifying how that principle can properly be regarded as supporting the offending premiss.

Wright raises a situation which certainly seems problematic at first blush. Suppose I wish to discover whether or not I am dreaming: I pinch myself (standard test).

By PEP, the result cannot be better warranted than the belief that I have properly executed the procedure is independently warranted; and that belief cannot be independently warranted at all unless I have independent warrant for its component, that I really did execute the procedure and did not merely dream its execution. But then it appears that I must already have the warrant which I have set myself to acquire. (p. 100, Wright's emphasis)

I pinch myself, and feel the pinch, so I cannot be dreaming: but suppose I dreamed the pinch?

Brueckner maintains that there is sleight of hand here. Suppose (I) $x$ 's belief that he is not maundering (not $M$ ) is such that he must acquire a warrant for it by proper execution of some procedure. Suppose also that (II) at $t_{0}, x$ first comes to acquire warrant for not $M$. Then:

(1) there is a $t_{1}$ when $x$ completes proper execution of the required procedure [I, II, PEP];

(2) there is a $t_{2}$ which is the earliest time at which $x$ has a warrant for believing that the procedure has been executed successfully [I, II, PEP];

(3) there is a $t_{3}$ when $x$ has a warrant for believing that he was not maundering when the procedure was apparently executed (and therefore has a warrant for believing not $\mathrm{M})(2, \mathrm{P} 2 * *$, Iterativity, Transmission).

We now have a serious problem given the assumption (III) that $t_{3}$ is earlier than $t_{0}$. But, Brueckner argues,

... how can Wright establish the necessary premiss III concerning temporal order? Suppose $t_{1}$ is earlier than $t_{0}: x$ completes the procedure and later comes to have a warrant for believing not $M$. Suppose further that $t_{0}=t_{2}$. That is, suppose that $x$ first comes to acquire a warrant for believing that not $\mathrm{M}$ at $t_{2}$, the earliest time at which he has a warrant for the belief that the procedure has been executed successfully. That is, once he has a warrant for believing that he has properly executed the procedure required for acquiring a warrant for believing not $M$, then he also has a warrant for believing not $\mathrm{M}$. Now what will preclude the possibility that $t_{0}=t_{2}=t_{3}$ ? Having a warrant for the belief that the procedure has been properly executed, according to Wright, requires having a warrant for believing that not $M$. But why should $x$ need a warrant for believing not $M$ before the earliest time $\left(t_{2}\right)$ at which he has a warrant for the belief that the procedure has been properly executed? (Brueckner 1992, p. 314, with many irrelevant changes) ${ }^{3}$

${ }^{2}$ Actually, of course, he wishes to focus on Wright's P1, but this is not a crucial change.

${ }^{3}$ This is a temporal argument. Brueckner also considers an independence argument,- 
Why shouldn't the following be the epistemological case: $x$ pinches himself, such action providing him with both the warrant that he is not maundering and the warrant that he did not dream that he pinched himself while in a maundering state? And if such were the case, then the PEP could not provide support for P1**, which in turn, as we shall see, is a crucial assumption for the sceptic. Hence, Wright's strategy of giving the sceptic as much as he wants has resulted in the sceptic being given an implausible premiss, and how could that help produce an exposé of the sceptic's power to seduce?

But the sceptic replies that, as long as we are being maximally congenial to him, we should respect his claim that all warrants based on perception are conditional on that perception being veridical (this is, of course, hinted at in the definition of the PEP). Suppose $x$ receives a load of perceptual inputs suggesting that he has pinched himself. Then, according to the sceptic, he is now warranted in believing that, if he is not maundering, then he pinched himself. The sceptic will also allow that it is a plausible principle that if $x$ wishes to establish that he is not maundering, and therefore pinches himself in order to carry out a procedure designed to establish that he is not maundering, and feels that pinch, then he is not maundering. ${ }^{4}$ If $x$ is not maundering, then, and is capable of competent intellection, the sceptic should allow that $x$ is warranted in believing that if he pinched himself then he is not maundering.

The upshot of all this is that the sceptic can insist that the proper execution principle only allows $x$, assuming that $x$ is not maundering, a warrant for the biconditional belief that he was not maundering if and only if he pinched himself. The conditionalizing sceptic will claim that at no time did $x$ acquire a warrant for the belief that he pinched himself, and similarly neither did he acquire a warrant for the belief that he was not maundering, and that therefore the proper execution of the procedure will not ground any of his beliefs. The warrant for any perceptually-based belief continues to depend on the warrant for the belief that $x$ is not maundering, and, for the sceptic, this latter is not forthcoming.

\section{Wright's complex argument}

Hence we can now proceed to Wright's argument with some confidence in the prima facie plausibility of both $\mathrm{P} 1 * *$ and $\mathrm{P} 2 * *$. Wright's paper is a long and involved one: we concentrate on the main destructive argument, to be found in $\S$ VII, pp. 105-8. This takes the form of a derivation of a sceptical conclusion, and the revelation that this conclusion actually harbours a hidden contradiction (and hence that $\mathrm{P} 1 * *$ and $\mathrm{P} 2 * *$ cannot both be true simultaneously).

The sceptical derivation runs as follows:

which he also finds lacking.

${ }^{4}$ Possibly, the sceptic is being a little over-generous here, since it might be the case that $x$ dreams that he pinches himself at the very moment that the index finger and the thumb of his left hand trap a section of skin from his right arm, but we will let that pass. 

(i.) $R x t[Q]$
(Assumption)
(ii.) $R x t[R x t[Q]]$
(i, Iterativity)
(iii.) $R x t$ [not: $M x t$ ]
(ii, P2**, Transmission, Modus Ponens)
(iv.) not: $R x t[Q]$
(iii, $\mathrm{Pl}{ }^{* *}$, reductio)

So, we have a sceptical result, that $x$ has no warrant at $t$ for believing suitable $Q$. $Q$, we recall, is any proposition for which $x$ can acquire warrant at $t$ only by competent intellection, and therefore admissible substituends for " $Q$ " include all those propositions which encode new information for $x$ at $t$, and which, because of the facts of $x$ 's life and the contents of those propositions, can only be accepted by $x$ warrantedly if he reasons competently. Wright's key thought here is that $2 * *$ is just one such proposition-and therefore can be substituted into the conclusion, (iv), to give us the following proposition:

not: $R x t$ [If $R x t[Q]$, then not: $M x t$.

But this is simply the negation of $\mathrm{P} 2 * *$, which was one of the premises used in the derivation of (iv.) The argument, as required, is contradictory-far from having produced a sceptical argument, what we have done is shown that this particular set of premises is inconsistent, that $\mathrm{P} 1 * *$ and $\mathrm{P} 2 * *$ cannot be simultaneously true. The sceptical conclusion was generated from unsatisfiable premises.

This, in itself, doesn't suffice to see off scepticism, of course, but the argument is the logical foundation on which Wright's imploding of the demon is based.

\section{The Sceptical Overkill Argument}

In Wright's paper, the move from $2^{* *}$ to $\mathrm{P} 2 * *$ (p. 107) was justified by analogy with a similar move (p. 97) from the thought that, where $P$ is a proposition that $x$ could come to believe at $t$ only by perception, and " $D x t$ " means " $x$ is dreaming at $t^{\prime \prime}$,

If $R x t[P]$, then not: $D x t$,

to the thought that

$R x t$ [If $R x t[P]$, then not: $D x t]$,

on the ground that, having established the former sentence for ourselves, there seems no reason to restrict $x$ 's capacities at $t$ so that he or she could not do the same. However, the thought arises that there may very well be a reason so to restrict $x$ 's capacities: he or she might be dreaming at $t$. This thought, though, is a harmless one, because dreaming need not necessarily preclude competent intellection.

But now, in the argument we are discussing, the move from $2 * *$ to $\mathrm{P} 2 * *$ seems much fishier. If $x$ and $t$ are arbitrary, then it is at least possible that $x$ is maundering at $t$, and therefore possible that he or she might be incapable of just the sort of competent intellection required for that move. Again, this respects the sceptic's point that our perceptually (and in the maundering case, intellectually) gained 
knowledge is conditional on our being in a fit state to acquire it. How does this observation affect Wright's argument?

Our observation says that we can only accept $\mathrm{P} 2 * *$ on the assumption that $x$ is capable of competent intellection at $t$. Hence we must replace $\mathrm{P} 2 * *$ with a new premiss:

O2**) If not: $M x t$, then $R x t$ [If $R x t$ [Q], then not: $M x t$ ].

If $x$ is not maundering, then he or she has a warrant for believing that, for appropriate $Q$, if he or she has a warrant for believing it, then he or she is not maundering at that time.

We can now develop a sceptical conclusion. $\mathrm{O} 2 * *$ has the form

If not: $M x t$, then $\mathrm{P} 2 * *$.

We know that $\mathrm{P}^{* *}$ and $\mathrm{P} 2 * *$ are not both satisfiable, thanks to Wright's argument. Hence the conjunction of $\mathrm{P} 1^{* *}$ and $\mathrm{O} 2{ }^{* *}$ will entail $M x t .^{5} \mathrm{Or}$, to put the quantifiers back in: for all $x$, at all times $t, x$ is in a phenomenologically smooth state which necessarily precludes the causal conditions for perception and competent intellection! Our sceptical conclusion is so far reaching that it is universally true of everything everywhere! We seem to have proved competent intellection impossible! For that reason, we call the argument the Sceptical Overkill Argument (SOA). ${ }^{6}$

\subsection{Responses}

Can we discover some way to avoid the dreadful conclusion of the SOA, even if we can't reinstate Wright's refutation? In this section we will discuss some possible responses that do not meet the challenge, and we will move on to an argument that has rather greater claims in $\$ 5$.

One response would be to deny that $Q$ ranges over $2^{* *}$ in the SOA. Recall that $Q$ was any proposition "which $x$ had no grounds for believing before $t$ and can acquire warrant to believe at $t$ only by competent intellection" (p. 102). Can this definition be interpreted so as to exclude $2 * *$ ?

${ }^{5}$ If this looks like sleight of hand, a Wright-style derivation (including $2^{* *}$ as a premiss) looks like this:
i. $\operatorname{Rxt}[Q]$
Assumption
ii. not: $M x t$
(i, $2^{* *}$, modus ponens)
iii. $R x t$ [If $R x t\{Q$ ], then not: $M x t]$
(ii $\mathrm{O} 2 * *$, modus ponens)
iv. $\operatorname{Rxt}[R x t[Q]]$
(i, iterativity)
v. $R x t[$ not: $M x t]$
(iii, iv, transmission, modus ponens)
vi. not: $\operatorname{Rxt}[Q]$
(v, $\mathrm{Pl} * *$, reductio)

Substituting $2 * *$ for $Q$ in (vi), (surely legitimate), we get:

not: $R x t$ [If $R x t[Q]$, then not: $M x t]$

which is, of course, "not: P2**". But P2** was not an assumption of this argument; the assumption we used was $\mathrm{O} 2^{* *}$, and between them, not: $\mathrm{P}^{* *}$ and $\mathrm{O} 2{ }^{* *}$ entail, via modus tollens and double negation elimination, $M x t$. My original paper contained this argument, but Crispin Wright and others alerted me to the quick version given in the text.

${ }^{6}$ Although he doesn't remember, Greg McCulloch thought the name up. 
There are two possible interpretations of the specification of $Q$. The first says that if $x$ can acquire warrant for $Q$ at $t$, then this can be done only by competent intellection. Under this conditional specification, $Q$ ranges over $2 * *$. The second interpretation says that $x$ can acquire a warrant for $Q$ at $t$, and that that warrant can be acquired only by competent intellection. Given this interpretation, it seems that $Q$ doesn't range over $2 * *$. Is this any help?

Sadly, no. In the first place, there is still the sceptical conclusion (that $x$ can have no warrant at $t$ for those $Q$ which are true under the new interpretation) to be dealt with (though this is much less destructive than the conclusion of the SOA). And in the second place, it is open to the sceptic to re-establish the SOA using our first interpretation. There is nothing inherently wrong with that interpretation, and to criticize it by showing that it allows the SOA to go through violates Wright's third constraint on any anti-sceptical argument. Only a win is allowed in the war against the sceptic, and if the only argument against the interpretation involves using the SOA itself as a contradiction for the purposes of a reductio then a question is being begged.

A more plausible way forward is a restriction, not of $Q$, but of $x$ and $t$. The SOA goes through on the assumption that the premises are implicitly universally quantified. There is very little textual evidence in Wright (1991) to confirm or deny this assumption, but an analogue of P1** was set up with arbitrary $x$ and $t$ on p. 97. Be that as it may, we can reinstate Wright's argument with non-arbitrary $x$ and $t$ as follows: choose some $x$ and $t$ so that everything is ideal for the antisceptics (and so in particular not: $M x t$ ). This, of course, was what Descartes attempted originally when he described himself sitting by the fire, etc., a paradigm case of someone perceiving. We can now run the Wright argument as before with ungeneralised premises, to get our conclusion, "not: Rxt $[Q]$ ". The sceptic can generalise from this: if there is no warrant in the best case, what hope is there for everyone else? But now, his move is blocked by Wright's reductio on the ungeneralised premises $\mathrm{P} 1 * *$ and $\mathrm{P} 2 * *$. My earlier complaint about $\mathrm{P} 2 * *$ cannot hold here, because the claim that it is universally quantified has been droppedthe claim now is only that it is going to be true in the best case. A version of $\mathrm{O} 2 * *$ could always be derived from $\mathrm{P} 2 * *$, of course (since $\mathrm{P} 2 * *$ entails $\mathrm{O} 2 * *$ ), and hence a restricted version of the SOA could go through. However, now there can be no danger, because $\mathrm{P} 1 * *$ and $\mathrm{P} 2 * *$ would still be premises for the new SOA, and Wright's argument has shown clearly that these premises are inconsistent.

However, this won't do it either; the sceptic can still come up dreaming that he smells of roses. By all means we can restrict the $x$ to some supposed best case. But the sceptic can always claim that it needn't be the case that "not: $M x t$ " follows from that. Why? Because, in the SOA, he has a perfectly good universally quantified argument whose conclusion is that $(\forall x, t) M x t$. Even in the best case imaginable, $x$ is maundering at $t$.

But suppose, in a rare fit of generosity, the sceptic allows the repaired Wright argument to go ahead. Will he be satisfied with the conclusion? There will be a contradiction, based on the following premises: 


\section{P1** \\ $(\exists x, t) \mathrm{P} 2 * *$.}

The sceptic will now surely insist that the second premiss be negated and discharged, here. He is not surprised at the contradiction arising, since this argument is equivalent to one with the following premises:

$$
\begin{aligned}
& \mathrm{P} 1 * * \\
& \mathrm{O} 2 * * \\
& (\exists x, t) \text { not: } M x t .
\end{aligned}
$$

And so of course a contradiction will emerge, since

$$
2^{* *}, \mathrm{P} 1^{* *}, \mathrm{O} 2 * *+\operatorname{not}:(\exists x, t) \mathrm{P} 2 * *
$$

and $2^{* *}$ is not in dispute.

What the anti-sceptic has to do now is to provide independent reasons for holding

\section{instead of}

$$
(\exists x, t) \text { not: } M x t
$$

not: $R x t$ [not: $M x t$,

for in the absence of such a reason, the sceptic has no other reason to withdraw his assertion of the latter. Indeed, he has positively excellent reasons not to do that, since he still has the universally quantified SOA, one of whose premises is not in doubt, and the other of which (not: $R x t$ [not: $M x t$ ]) is at least plausible (though it is now clear, after the argument of this section, that this is the premiss that has to go in order to overturn the SOA). The result of this discussion is that, even with the reform of the Wright argument, the third of Wright's original constraints will be violated-at best this is the draw that is not good enough.

\section{The Wright response}

A more promising response was suggested to me by Wright ${ }^{7}$ that trades on the notion of a second order argument. Recall that a second order counterpart of a sceptical argument is the argument that results when the sceptic moderates his claim that the original premises are true, and falls back on the claim that at least there is no warrant for asserting their negation. Suppose that the sceptic retreats from the SOA to the second order counterpart. Then he will want to make play with

$$
\text { If } A x t\left[\mathrm{P} 1^{* *}, \mathrm{O} 2 * *\right] \text {, then } A x t[M x t] \text {. }
$$

i.e. if we are agnostic with respect to $\mathrm{P} 1^{* *}$ and $\mathrm{O} 2^{* *}$, then we should be agnostic about $M x t$. This sentence, by definition of the " $A$ " operator, is equivalent to

If not: $R x t$ [not: $\left(\mathrm{P}^{* *} \& \mathrm{O} 2^{* *}\right)$ ], then not: $R x t$ [not: $M x t$ ]

\footnotetext{
${ }^{7}$ Wright suggested this response to me some time ago. I do not know whether he still
} endorses it, but even if not it is clearly interesting enough to merit discussion. 
The consequent of this is $\mathrm{P} 1^{* *}$, and so the second order SOA gives us a new argument for that controversial premiss. However, the argument will convince only if the antecedent is credible independently of a prior commitment to the conclusion. But to establish the antecedent, $A x t\left[\mathrm{P} 1^{* *}, \mathrm{O} 2 * *\right]$, will involve establishing both $A x t\left[\mathrm{P} 1^{* *}\right]$ and $A x t\left[\mathrm{O} 2^{* *}\right]$. The latter seems plausible enough. However the former expands into

$$
\text { not: } R x t \text { [not: } \mathrm{P} 1^{* *} \text { ] }
$$

which, via double negation elimination and iterativity, is just $\mathrm{P} 1 * *$ again. So making a case for the antecedent of the second order SOA involves making a case for its conclusion, so the second order SOA cannot help the sceptic acquire a warrant for its conclusion.

The upshot of this is that the anti-sceptic can now stick to dissolving the first order SOA - the sceptic has no easy cushion of a second order argument to fall back upon. The proposal now, in that case, is to show that there is no simultaneous warrant for each of $\mathrm{P}^{* *}$ and $\mathrm{O}_{2 * *}^{*}$. If it is indeed the case that there is no simultaneous warrant for the two premises of the SOA, then the anti-sceptic can simply say that the SOA is interesting only if we have the abilities to recognise the rational warrants for its premises. If we do not have these abilities, then the sceptic will fail to worry or engage the alert interlocutor.

It turns out to be quite straightforward to show that for all $x$ and $t x$ is not warranted in believing both $\mathrm{P} 1^{* *}$ and $\mathrm{O} 2^{* *}$ simultaneously. Suppose $x$ is maundering at $t$. Then he is not warranted in believing anything, from $2^{* *}$ (which the sceptic, of course, accepts). But suppose $x$ is not maundering at $t$, and has warrant for $\mathrm{P}^{* *}$ and $\mathrm{O} 2 * *$. Then it follows by transmission, since $\mathrm{P} 1{ }^{* *}$ and $\mathrm{O} 2 * *$ entail $M x t$, that $R x t$ [Mxt]. $x$ is not maundering, so modus ponens on $\mathrm{O} 2 * *$ gives us $\mathrm{P} 2 * *$. Substituting " $M x t$ " for " $Q$ " in $\mathrm{P} 2 * *$ gives us

$$
R x t \text { [If } R x t[M x t] \text {, then not: } M x t \text { ]. }
$$

But we know that $R x t$ [Mxt], so by iterativity and transmission, $R x t$ [not: $M x t$ ]. But the definition of warranted belief that Wright suggests in his original paper is such that one cannot be warranted simultaneously in two contradictory beliefs. Hence, whether or not $x$ is maundering at $t, x$ cannot have warrant to believe both $\mathrm{P}^{* *}$ and $\mathrm{O} 2^{* *}$ simultaneously ${ }^{8}$, and hence the SOA, devastating though its conclusion undoubtedly is, should never impress anyone.

${ }^{8}$ Note that, although $\{$ If $A$ then $B$, If not: $A$ then $B$ \} does not entail $B$ intuitionistically because of a crucial double negation elimination step, $\{$ If $A$ then not: $B$, If not: $A$ then not: $B$ \} does entail not: $B$ intuitionistically, since there is no double negation elimination in the proof of that. Hence Wright's result here is intuitionistically valid. However, the waters are generally murkier in an intuitionistic context, since the earlier equivalence between the statement that Axt [PI**], that there is no warrant to deny $\mathrm{PI}^{* *}$, and $\mathrm{PI}^{* *}$ itself, which was so important in the discovery that there was no second order equivalent of the SOA, is not intuitionistically provable. 


\section{The sceptical entrenchment}

The question now is: how convincing is that reasoning? One possible weak spot is the substitution of " $M x t$ " for " $Q$ " in P2**. It might be thought that " $M x t$ " is a particularly poor candidate for a proposition which $x$ has no grounds for believing before $t$, and can acquire warrant to believe at $t$ only by competent intellection (which of course is the specification of the possible substituends for " $Q$ " in $\mathrm{P} 2 * *)$. There is no avenue of protest here, however: on the assumption that $x$ has warrant for $\mathrm{P} 1^{* *}$ and $\mathrm{O} 2^{* *}, x$ does acquire warrant for " $M x t^{*}$ " precisely by competent intellection, thus enabling Wright's new reductio to go through!

However, the sceptic will claim that something fishy is going on. Wright has shown that, even on the supposition that $\mathrm{P}^{* *}$ and $\mathrm{O} 2 * *$ are both true, no-one can ever be warranted in believing both of them. But that is a result that the sceptic himself will push, and has been since the discovery of the SOA. If $\mathrm{P} 1 * *$ and $\mathrm{O} 2 * *$ are both true, then everyone is always maundering and competent intellection is impossible. Hence, we shouldn't be surprised that we get a contradiction from the second horn of Wright's dilemma; if we assume that $x$ is not maundering at $t$, and we also assume that he has warrant to believe two premises that together entail that he is maundering at $t$ and therefore can have no warrant to believe anything, then contradiction is bound to result. The sceptic now, fortified by the SOA, claims that only the first horn of Wright's dilemma-that $x$ is maundering at $t$ is always going to be the case, and that therefore no-one has any warrants for anything.

When formulating his second constraint upon any anti-sceptical argument, Wright says:

Consider the mythical glass-chinned sceptic who claims that there is no reason to believe anything at all. Nothing easier than to confound such an opponent in debate. But if you yourself are led, in camera as it were, to that absurd conclusion by a seemingly well-motivated route, it is no intellectual comfort to reflect that the position is self-defeating. (p. 89)

What we need to meet the second constraint is a detailed diagnosis of the problem, as Wright points out. The Wright response to the SOA is sufficiently powerful to show that the route by which one is led, in camera, to the absurd conclusion is not well-motivated; and in that respect is, I think, entirely successful. However, the question may still remain as to whether the sceptic has been confounded-the sceptic's own reasoning with the SOA leads to the clear conclusion that no route anywhere is ever well-motivated. There are two interpretations of the second constraint: 1) defusing a paradox involves showing why the premises are unconvincing; 2) defusing a paradox involves showing that at least one of the premises is false. If we can show that there is, anywhere, anybody who warrantedly believes any proposition of an appropriate sort, then that demonstration would complete the job on either interpretation. But the Wright response leaves the situation absolutely consistent with the sceptic's wild SOA-inspired claims, and therefore can only really be said to work on the first interpretation. If $\mathrm{P} 1 * *$ and $\mathrm{O} 2 * *$ are simul- 
taneously true, then we have no warrant for anything at all, a fortiori no warrants for $\mathrm{P} 1{ }^{* *}$ and $\mathrm{O} 2{ }^{* *}$ (also, of course, we have no warrants to deny either $\mathrm{P}{ }^{* *}$ or $\mathrm{O} 2 * *$; the second order SOA would then give us $\mathrm{Pl} * *$-were we capable of grasping it!). The sceptic's conditionalization tactic appears to leave him in the clear, even given Wright's response. If I am not maundering now, then I should not be convinced by the sceptical reasoning, the response tells us-which is nice to know, of course, but there may be some epistemologists who would feel that this is only a partial exposé of the sceptical project.

Hence, Brueckner's argument about pinching oneself (i.e. the correct application of an appropriate procedure) was at least a more promising route to confounding the sceptic. Warrant to believe anything of the appropriate sort gives us the warrant to deny the sceptical conclusion of the SOA. Wright's arguments provide further ammunition to those who would wish to argue-surely correctlythat the position is self-defeating, but Brueckner's strategy is cleaner for those who wish to claim that the position is simply false.

However, we have noted that Brueckner's arguments do not work if the sceptic wishes to conditionalize the relevant sentences. And, in fact, might we not locate the extraordinary resilience of the sceptical project with the sceptic's constant insistence on the conditionalization of his various premises? Consider, for example, the conclusion of Wright's response: that we have no warrant for simultaneously believing $\mathrm{P} 1{ }^{* *}$ and $\mathrm{O} 2 * *$. This conclusion can only be reached warrantedly on the basis of competent intellection. But the sceptic will now wish to claim that, by (some variant of) the PEP, one's warrant to believe that there can be no simultaneous warrant for the offending premises is dependent on competent intellection being a possibility. Let us introduce an indexical term " $M m n$ " (maundering (me, now)), meaning that the person uttering or writing that formula is maundering at the time of utterance or writing. Then, the sceptic will say, what it is correct to write after a careful study of Wright's response, is

If not: $M m n$, then not: $R x t\left[\mathrm{P} 1 * * \& \mathrm{O}_{2}^{* *}\right]$,

which doesn't really help against the sceptic (except as a further aid towards the anatomization of the "self-defeatingness" of the sceptical position) without the assumption that not: $M m n .^{9}$

Artificial Intelligence Group

Department of Psychology

KIERON O'HARA

University of Nottingham

Nottingham NG7 2RD

$U K$

\section{REFERENCES}

Brueckner, A. 1992: "Problems with the Wright Route to Skepticism". Mind, 101, pp. 309-17.

${ }^{9}$ I am extremely grateful for discussions with Crispin Wright, Greg McCulloch and Tim Williamson on this topic. 
Sceptical Overkill: On Two Recent Arguments Against Scepticism 327

Wright, C. 1991: "Scepticism and Dreaming: Imploding the Demon". Mind,100, pp. 87-116. 